\title{
To heal or not to heal, physician, that is the question
}

\author{
Kernan Manion \\ Executive Director CPR, The Center for Physician Rights
}

\begin{abstract}
Physicians experience mental illness, substance abuse and burnout at comparable to considerably higher rates than the general population. However, they face great risk if they acknowledge on licensing and credentialing application queries the fact of their seeking help or that they have sought such in the past. Physicians also risk allegation of having such disorders, especially by any of three major regulatory powers which have authority over their professional licenses. These entities can mandate so-called Psychological FitnessFor-Duty Evaluations (PFFDE) by non-neutral evaluators and then compel acceptance of their findings and immediate and full compliance with their recommendations, doing so in an environment devoid of due process and with no discernible recourse for the subject physician. This article strives to highlight this previously unrecognized peril and encourage further exploration of these concerns and undertaking of collaborative measures to ensure that physicians can obtain professional help when needed without causing career jeopardy while also honoring the valid quality of care and patient safety concerns of the prevailing regulatory entities.
\end{abstract}

\section{Introduction}

Imagine an admonition that went against all commonly accepted wisdom: Physician, don't heal thyself... and whatever you do, don't be seen seeking healing. One that even added: In fact, be very cautious about even acknowledging that you yourself need healing.

It would be understandable if you winced, greeting such a caveat as so incredible as to only be imaginable in some medical version of George Orwell's 1984. Alas, as we've witnessed over recent years, Orwell's dystopian fantasy was quite prescient.

\section{Physicians get ill and have substance abuse problems?}

Brace yourself - this may come as a shock. Physicians are human beings, and while often exceptional and resilient, they are not immune from succumbing to emotional illness, substance abuse or professional burnout.

Correspondence: Kernan Manion, One Mifflin Place at Harvard Square, Suite 400, Cambridge, 02138 MA, USA.

Tel.: +1.978.381.3880

E-mail: cpr@physicianrights.net

Key words: Physician; board; PHP; peer review; fitness-for-duty.

Received for publication: 6 November 2019.

Accepted for publication: 27 November 2019.

This work is licensed under a Creative Commons Attribution NonCommercial 4.0 License (CC BY-NC 4.0).

${ }^{\circ}$ Copyright: the Author(s), 2019

Licensee PAGEPress, Italy

Qualitative Research in Medicine \& Healthcare 2019; 3:126-135 doi:10.4081/qrmh.2019.8665
(For this paper, the term 'physician' throughout refers to licensed Medical Doctors, MD or DO or international equivalent, including physicians in postgraduate training, i.e. interns and residents, and to medical students.

There is abundant literature documenting the yearly incidence of significant depressive symptoms in nearly a third of trainees and roughly the same for med students. So too the significant incidence of other emotional illnesses. And, in a study of alcohol abuse, in this case amongst surgeons, the incidence of such approximately $20 \%$. As this is not an epidemiologically oriented treatise, for our purposes, let's posit that approximately a quarter to a third of the practicing physicians in the US currently grapple with emotional illness or substance misuse; and when considered cumulatively, the prevalence of these escalates markedly. Whether these illnesses rise to the level of impairment that significantly affects one's performance at work is a crucial question. In fact, it may be one of the central questions underpinning legal arguments which challenge the alleged right of intervention of regulatory entities into one's personal life. That question must be relegated to legal scholars and will not be addressed here.

This paper aims to explore a previously under-recognized major hindrance to physicians seeking mental health and substance abuse care and one that paradoxically may be causing new or worsening psychopathology.

\section{An illustrative case}

Consider the following composite scenario: a wellliked internist, Dr J., had recently taken a brief medical leave due both to chronic and severe work life stress and urgent family issues. She confidentially queried a few of her colleagues on their recommendations and independently sought psychiatric care. Diagnosed with depression in the context of serious burnout, she was begun on an antidepressant and also entered into psychotherapy. After 
two weeks of approved leave, she returned to her clinical and leadership role without event and with full resumption of her duties.

That month, her state medical license application was up for its three-year renewal; it asked if she had ever had a mental illness or been on medication for such and whether she had ever had problems with substance abuse. Naive, and believing she had to disclose her recent initiation of psychiatric treatment, she answered that she had. She was subsequently notified by the Medical Licensing Board (MLB) that she would need to schedule an assessment at the state's Physician Health Program (PHP). Believing this to be little more than some form of routine clearance visit, she scheduled this evaluation.

Upon arriving, she was informed that, simply on protocol, she had to submit to an observed urine screen for drug testing. She then sat for a 90-minute interview with the PHP intake social worker who conducted a highly personal mental health consultation. During this assessment, upon being questioned about her alcohol use, she acknowledged that she consumed alcoholic drinks several times weekly and also upon further inquiry affirmed that, yes, during the peak of her burnout, she did notice that her pattern of drinking increased but not to any problematic degree and certainly not to incur any legal charges or adverse impact on patient care.

At the conclusion of this interview, concerns were raised by this social worker and the non-physician clinical director about her evaluation and specifically her use of alcohol. While she thought their concerns were overly cautious, she left confident that all had been explained satisfactorily.

Several days later, she received correspondence from the PHP indicating that they were recommending that she attend a four-day comprehensive fitness-for-duty evaluation out-of-state at a specific PHP-approved facility - at an out-of-pocket cost of nearly $\$ 5000$ - allegedly to determine whether she had a substance abuse problem and whether she was truly safe to practice. In calling to clarify, she was informed that, as her urine drug test for alcohol was elevated, they felt her attendance at this purportedly specialized assessment program was mandatory and that if she declined to participate, it was likely that when the PHP informed the MLB, the MLB would officially compel her compliance with their recommendation as a condition of licensure. As she reviewed this with incredulity, her concerns were only heightened in learning of similar stories of physician colleagues who were coerced into such four day evaluations and then ordered into lengthy treatment followed by five years of intrusive and costly PHP monitoring.

She feared asking for a copy of her PHP evaluation but felt that she needed it just to be able to make sense of what they were basing their findings and recommendations on. She was told that she could not obtain that as it was privileged information.
Should she refuse to comply, the Board would not renew her license. Thus, she would lose her privileges at her hospital and would be reported to the National Practitioner Data Bank, making her virtually unemployable anywhere. But should she comply and sign a contract to become a 'participant' in the PHP program, she risked being labeled as an 'impaired physician' which would subject her to strict compliance with a state-enforced PHP-managed treatment and monitoring program.

She notified the chief medical officer at the hospital where she was a longtime employed physician. While the executive leadership at her hospital held her in highest esteem, they told her that they were bound to enforce compliance with whatever the PHP and MLB ordered. At considerable expense, she hired a professional license defense lawyer, a former Board attorney himself, who matter-of-factly opined that she should comply simply out of expedience as the Board had the right to suspend her license immediately if she challenged this. And should she decide to fight it, the legal effort would be protracted, very costly and likely futile. And besides, he cautioned, it would likely anger the Board.

\section{Discussion}

While the above is a composite reconstruction of a representative case, the reality is that variations of this scenario repeat with alarming regularity. Hundreds if not thousands of physicians each year may find themselves ensnared in such a Kafkaesque nightmare.

But, absent actual documented concerns about her current clinical performance, it is unlikely that there is any legitimate basis for a MLB or PHP to order or conduct such an investigation simply on the basis of such intrusive licensure application questions. Numerous authors have raised concerns about the very legitimacy of certain questions MLBs and credentialing bodies ask on their applications, opining that such questions are in overt violation of the Americans With Disabilities Act (ADA). And there is significant data to support that.

But there is a world of difference between having rights and exercising them, especially in an administrative regulatory system untethered from any state oversight and free from liability for abuse of its power. And clearly there is more here than simply the legality of asking such intrusive questions on a licensing or credentialing application.

\section{The chaos and turmoil sequelae of PHP Engagements}

When 1 more closely examines the cascade of events that has occurred, the decisional quandaries it poses and the future implications of whatever course of action she chooses, it is no surprise that Dr J. found herself incredulous and immobilized.

It is fair to say that so much has happened in such a short period of time with such immense implication that 
truly the mind can't unpack it. I have come to understand it as intrapsychic chaos and turmoil. The chaos is from too many events, issues and situations of awesome importance occurring virtually simultaneously, each demanding a reasoned internal dialog but because of its urgency, that dialog rising to the level of panicked cacophony. The accompanying emotions - anxiety and fear, hurt and powerlessness, anger, shame ... all flood forth as well. So much intrapsychic congestion occurs that it is literally impossible to tease apart expediently. It overwhelms the RAM capacity of the mind. And like illness, the longer the chaos and turmoil continues, the more relentless the erosion of resilience and wellbeing.

\section{The Sequelae in Slow Motion}

As one dissects this not atypical scenario, note the host of issues occurring concurrently. She had no idea the farreaching implications of submitting to such an evaluation. All she knew was that she had long-simmering but adequately managed burnout which acutely intensified; that she developed serious depression, and that she was relieved that she was wise enough to get help and was on the mend. She was pleased to be back in the groove and her colleagues were thrilled to have her back.

She was initially more irritated than worried about the Board's insistence on submitting to the PHP assessment before renewing her license. She really thought it was just a pro forma thing that Boards do; after all, she had never answered such a mental illness question in the affirmative before. She thought it was a bit intrusive but reasoned, after all, it must be legitimate for them to ask these questions, otherwise they would not. Her medical society of which she was now president-elect had never raised any issues about it.

She was taken aback by the unannounced observed urine drug testing, thinking nothing of her routine social use of alcohol. But she was bothered that in questioning why this test was necessary, she was matter-of-factly told it was part of their protocol. Neither she nor her psychiatrist had had any concerns about her social drinking, including while she was on an antidepressant. She was simply cautioned, just keep it very moderate and do not drink to excess.

She was very troubled by the intrusive PHP intake questioning. It felt like an intensive psychiatric assessment, delving into her past medical and psychiatric history including her sexual assault in college, and asking deeply personal questions about her marriage and other family matters, and the impact of her burnout on her clinical work, and whether she felt it had any adverse impact on her patient care. She recalled being asked what would your colleagues say about your work and immediately it crossed her mind that she feared that they would actually call some of them including one colleague who was vying for her leadership position and seemed to take every opportunity to cast her in a negative light.

She did not know what her rights were and whether she should demand the full PHP report that they already said she had no right to, or simply let a lawyer deal with it. She felt it was deeply unfair but then again, apparently it was their right. She found herself worrying that they would even share their findings with her colleagues on the medical executive committee at her hospital.

She was deeply unsettled not only by being advised that she should go to some unusual and costly four-day assessment program out of state, but that, if she did not, the PHP had the right to not only report her to the Board as being non-compliant but, subsequently reviewing her signed disclosure consents, might actually share the entirety of her psychiatric report with them. That the Board would actually enforce such a recommendation seemed unconscionable, incomprehensible. But further, she was incredulous that a highly recommended lawyer who routinely represented physicians in matters before the Board told her that there was essentially nothing that she could do; even if she challenged it, she would not win. And it would cost tens of thousands of dollars and while she was challenging it, the Board would demand the suspension of her practice in order to ensure that she was safe to practice and to protect the public. That was their right, he said, nodding sternly, and it was their duty. She was told it could go on for years!

Needless to say, her emotional stability in her early period of recovery from burnout and depression became quite tenuous. As her depression worsened and her anxiety intensified and now necessitated another leave from work, her psychiatrist was tempted to add medications to her regimen but her therapist who patiently enabled her to elaborate her story encouraged holding the course so that the two of them could sort out this avalanche of stresses.

\section{'Physicianhood' stress is normalized}

It is fair to say that the average physician's professional life is quite stressful, many would argue immensely more so than most other professionals. That stress takes a toll. Numerous studies report a mind-boggling incidence of burnout as high as $50 \%$ of the actively practicing physician population. So, prevalent is burnout that it has recently garnered its own World Health Organization (WHO) diagnosis code, though it appears that this is the sort of code that is used simply to connote a focus of treatment and not a defined mental illness per se. Some researchers now are arguing that burnout is really just another form of depression and ought to be treated clinically.

Chronic stress itself diminishes resilience and increases the likelihood of new occurrence of emotional illness and substance abuse. It is well known to fuel maladaptive responses in professional and personal life, e.g. inappropriate reactivity in communication and behavior (as is characteristic of disruptive behavior). In 2007, I presented 'Burnout and Its Toll on Physicians' for the Federation of State Medical Board's (FSMB) six session conference. An Epidemic of Disruptive Behavior among 
Physicians - A Web Conference: Clinical, Legal, and Disciplinary Perspectives and proposed that burnout was a significant driver of disruptive behavior.

Fortunately, over the prior decade, there has been an intensified interest in understanding physician burnout and exploring remedies. Some recent articles reference studies that have begun to explore burnout's potential impact on errors and patient safety.

The National Academy of Medicine (NAM) held a resource-rich conference in 2018 - The Action Collaborative on Clinician Well-Being and Resilience which STAT News highlighted. In the comments section of the STAT article (https://www.statnews.com/2018/02/15/clinicianphysician-burnout-resilience/), I raised multiple concerns about the nebulous notion of 'potential for impairment' and the dangerous leeway that term provided for even more aggressive intervention by MLBs and PHPs and conceivably even peer review (PR) entities. While certainly a well-motivated initiative, this new hypothesized linkage amongst burnout, depression and increased risk of clinical error affecting patient safety could have a paradoxical effect, essentially serving as a trifecta enabling MLBs, PHPs and PR entities to perceive that they have even more license to compel psychological ... assessments (PFFDEs).

Also worrisome is the Federation of State Physician Health Program's (FSPHP) recently revised PHP Guidelines which newly describe medicine as a 'safety-sensitive profession'. Such subtle labeling also may enable increased scrutiny of complaints about physician behavior, even anonymous ones bearing no objective basis, leading to a lower threshold for ordering stat drug testing in situ and compulsory fitness for duty assessments simply on suspicion.

Independent of any medical regulatory or other concerns, finding knowledgeable and relatable mental health care and specialized professional life coaching (e.g. for burnout) can indeed be a challenge in and of itself, not to mention the pragmatics of actually engaging such services, independent of whether the MLB, PHP or PR entity is involved.

\section{The dangers for physicians seeking mental health care}

\section{Physician unawareness and naïveté}

Perhaps it is because of the apparent integrity and quality controls of our training institutions that physicians have tremendous trust in the integrity of the medical regulatory systems. And for most who have no disciplinary or alleged suboptimal performance allegations, these are simply benign bureaucratic administrative entities that operate in the background.

Under ordinary circumstances, an article detailing the rising incidence of mental illness, substance abuse and professional burnout might simply focus on why it is important that physicians have ready access to and actually pursue confidential, high quality mental health care. If you have depression, anxiety or any other form of emotional distress or illness, or a substance abuse issue, or even both, you'd be encouraged to make arrangements to get the help you need. Just as in any other initial medical consultation, that help may entail a diagnostic psychiatric evaluation and perhaps being prescribed medication and psychotherapy (i.e. talk therapy). And it may entail other evaluations or treatment, e.g. marital counseling, or substance abuse assessment that that evaluator / treater may not have expertise in. While perhaps embarrassing or inconvenient, physicians should be able to avail themselves of these services without adverse consequences.

However, in the current medical regulatory environment, especially with such intrusive and likely ADA-impermissible questions on medical licensing and credentialing applications, that is not the case - at all. In fact, it may be quite dangerous to seek mental health care.

With the emergence of the PHP movement, physicians came to be considered a special breed of professionals whose illnesses require aggressive intervention by governmental authorities to confront their denial of their lurking illness in order to 'protect ... safety'. The 2019 FSPHP Guidelines state:

Today, the PHP model of care management includes physicians and other healthcare professionals and occurs with the knowledge that i) addictive, psychiatric, or other potentially impairing conditions may be chronic relapsing conditions, and ii) without appropriate treatment and accountability, individual health and public safety are at risk

\section{Compulsory (and potentially impermissible) disclosure}

In contrast to the privacy rights of ordinary citizens and members of other professions, on very questionable grounds a physician may be mandated to reveal the existence of a current or past mental illness or substance use disorder and its treatment. These licensing and credentialing entities have the perceived (or perhaps actual) authority to ask on application invasive questions about your current or past mental health or substance use history. For example:

Within the past 5 years, have you ever raised the issue of consumption of drugs or alcohol or the issue of a mental, emotional, nervous, or behavioral disorder or condition as a defense, mitigation, or explanation for your actions in the course of any administrative or judicial proceedings or investigation; any inquiry or other proceeding; or any proposed termination by an educational institution; employer; government agency; professional organization; or licensing authority? (from Alabama medical license application). ${ }^{2}$

Now, it is not simply the invasiveness of one's privacy and concerns about confidentiality that is the issue, though this is no small matter. It is what happens when you've answered in the affirmative: you can be ordered into a 
state-run diagnostic assessment and treatment program accompanied by lengthy monitoring.

After you have disclosed having such diagnoses and/or obtaining treatment for such conditions, even though in the past and having no impact on one's current professional or personal life, various state and corporate powers have the actual or perceived authority not only to insist, independent of any consideration of your current professional performance, that you get an evaluation. They can also demand that you receive treatment whenever these entities determine that you need such, and that you do so at the 'preferred provider' of their choosing.

There are at least six profoundly concerning components to this: i) you may be forced to disclose legally protected utmost confidential personal matters including your mental and physical health history and family history (this is designated in various laws as 'PHI - Protected Health Information'); ii) that upon some ill-defined and unwarranted determination by a Medical Regulatory Therapeutic Complex (MRTC) entity, you may be ordered to submit to an invasive psychological fitness-for-duty evaluation; iii) you may be required to unquestioningly accept its findings; iv) you may be required to immediately comply with the prescribed treatment no matter what it may be; v) such assessments and treatment are to be conducted by any clinical or perhaps even non-clinical provider the state or corporate entity chooses; and vi) you have no right to contest this in any manner. Should these raise concerns? One would think so.

\section{The Medical Regulatory Therapeutic Complex - MRTC}

MLBs, PHPs and PR entities, including performance appraisal (PA) systems as seen in academic departments and residency training programs, each serve a legitimate if not critically important function; they are not in and of themselves bad or constructed to be harmful.

In studying the interrelatedness of these regulatory entities, Emmons and coauthors described a seemingly independent but in actuality an aggregated system that works as a cohesive regulatory enterprise with awesome license and credential-determining - and thus potentially career-ending - power over the subject physician. They termed this entity the Medical Regulatory Therapeutic Complex (MRTC).

However, alarmingly there is no discernible oversight of this immensely powerful MRTC system as a whole and often no oversight of the individual entities comprising it. Its individual entities enjoy a virtually iron-clad immunity from prosecution for their activities and may deny any legal recourse for the affected licensee. All three entities operate virtually free of the constraints of due process, emboldened by their implied permission to act in this manner under the vague but broad banner of 'protecting the public'.

When any human system operates without oversight and free of accountability, it is vulnerable to corruption and susceptible to dramatic deviance from ethical and even legal bounds. As an example, note the propagation of the alleged legitimacy of denying due process to PHP clients as casually mentioned in the FSPHP's Physician Health News:

PHPs also assist boards in their ability to respond more rapidly, as they are not burdened with 'due process' requirements. State PHPs function as a clinical arm for regulatory boards.

Note also their distinct declaration of non-neutrality.

\section{Medical Licensing Boards (MLBs)}

MLBs have immense authority to discipline physicians and to intervene in cases of impairment and unprofessional behavior. MLBs become involved in this arena in a number of ways. A patient or colleague complaint may have been submitted about the physician's behavior. In this setting, in stark contrast to the manner that complaints about lawyers must be submitted to the state bar, anonymous complaints are permitted. And MLBs themselves, even absent any external complaint, may be the genesis of such complaints, acting 'on their own motion'. The physician may be deprived of responding to the complaint, even prevented from seeing it with the complainant identity concealed.

While a MLB may conduct an investigation into the complaint (the operative parameters of such investigations remain quite obscure), in matters relating to any mental health or substance abuse issue, the MLBs as a general rule send such cases to the PHP for evaluation. Surprisingly, there appears to be no way at this pivotal moment to challenge the basis for this compulsory referral given the wide legislatively granted power of MLBs. As an example of this authority, here is the MLB's authority as written in the North Carolina General Statutes:

$\S 90-14$. Disciplinary Authority.

(a) The Board shall have the power to place on probation ... require satisfactory completion of treatment programs ... fine, deny, annul, suspend, or revoke a license ... any person who has been found by the Board to have committed any of the following acts or conduct, or for any of the following reasons:

(3) Made false statements or representations to the Board, or willfully concealed from the Board material information in connection with an application for a license .... [thus, physicians' concern about not disclosing treatment for mental illness or substance abuse, notwithstanding whether such questions may be impermissible] (5) Being unable to practice medicine with reasonable skill and safety to patients by reason of illness, drunkenness, excessive use of alcohol, drugs, chemicals, or any other type of material or by reason of any physical or mental abnormality. [you will note that 'excessive' is not defined and that the scope of this authority is apparently not 
time-bound] The Board is empowered and authorized to require a physician licensed by it to submit to a mental or physical examination by physicians designated by the Board before or after charges may be presented against the physician, and the results of the examination shall be admissible in evidence in a hearing before the Board. [this permits complete disclosure of one's PHP and preferred partners' records including that compiled from the polygraph interrogator.]

(b) The Board shall refer to the North Carolina Physicians Health Program all licensees whose health and effectiveness have been significantly impaired by alcohol, drug addiction or mental illness. .... [note that 'effectiveness' and 'significantly impaired' are not defined, nor is the manner of determination of these parameters by the MLB]

(e) The Board and its members and staff shall not be held liable in any civil or criminal proceeding for exercising, in good faith, the powers and duties authorized by law. [this establishes the MLB's immunity; in a later section, similar immunity is codified for the exclusively contracted, MLB funded PHP].

Modeled after the Federation of State Medical Board's (FSMB) 'Model Medical Practice Act', many of the elements here are common to other states' statutes.

\section{Peer Review / Performance Appraisal (PR/PA)}

Hospitals' medical staff bylaws generally delineate the role of quality assurance and peer review of physicians. While an outgrowth of the Quality Assurance / Continuous Improvement movement amongst corporations in the business sector, peer review is an activity further defined and protected by the federal law known as the Health Care Quality Improvement Act or HCQIA. While it outlines a fair and confidential clinical care review process conducted within an environment of due process, many have found that protections for physicians who feel they have been subject to a wrongful or Sham Peer Review (SPR) are so weak as to be non-existent. Dr Lawrence Huntoon has written extensively on the phenomenon of sham peer review.

While PR / PA may not directly initiate its focus on allegations of physicians' mental illness or substance abuse or seeking treatment for these, the PR / PA process may opine that a physician presents a matter of concern that seems to exist in this area and therefore may compel that that physician undergo assessment and perhaps treatment. It is in this manner that a PR / PA may then mandate such PFFDE and treatment, generally through the state's PHP program which this referring entity may genuinely believe to be an independent, benevolent licensed mental health organization. A sham peer review may use such allegations in a hostile manner to establish a pretext of concern while also activating this costly mechanism to consume inordinate resources and effectively derail a physician's career.

Given the absence of internal and external oversight of this process as well as of the MRTC as a whole and negligible protection against abuse, the potential for irreversible derailment of a physician's career via wrongful accusation, hostilely motivated proceedings and a mandated referral process to a non-neutral non-overseen governmental entity is quite significant. Once this cascade is begun, it can quickly become perilous and costly. Finding specialized counsel knowledgeable in these matters may be challenging.

\section{Physician Health Programs (PHPs)}

It appears that many PHPs are the offspring of state medical societies and often remain contractually and even corporately affiliated with them. In addition to their circumscribed legislatively granted authority, they may also enter into a memorandum of understanding not only with their parent organization and the MLB but with other specialty societies as well. In fact, PHPs may contract to become the exclusive 'impaired professional' evaluator for diverse other medical professionals, e.g. veterinarians, pharmacists, dentists et al.

It is important to note that, while some (apparently a minority) have a psychiatrist on their staff, the PHPs are not offshoots of any organized psychiatric entity. However, many licensees and healthcare organizations are under the mistaken impression that these are legitimate psychiatric entities. The absence of such a professional identity, coupled with PHPs' penchant for denying that they even conduct diagnostic psychiatric assessments at all, seems to free them from abiding by prevailing and professionally binding psychiatric ethics in the conduct of their weighty forensic activities while operating under the appearance of benevolence and neutrality.

PHPs necessarily conduct some form of diagnostic assessment and do so on direct referral from an external entity like one's employing hospital; on a physician's self-referral; and on referral of the MLB which is generally not a referral but a Board order.

However, as they may be identified as the exclusive program for Board-related matters, with the state defining its rights and operational parameters in both statute and administrative code, it's important to note that each state's PHP may be organized differently and operate under other legislatively granted power or perhaps none at all.

\section{The problem with PHPs}

In theory, PHPs are a promising endeavor. Born out of local hospital impaired physician committees, they were initially intended to serve as a benevolently motivated program for physicians who were manifesting problems with substance abuse, predominantly alcohol though narcotic and other drugs of abuse were also in their purview. As such behavior was rightfully seen as an ill- 
ness, PHPs sought to protect physicians from disciplinary action, proposing to engage them in a treatment program. Thus, PHPs served as a form of a non-disciplinary Board diversion rehab program.

However, as PHPs expanded their scope of diagnostic concerns (just as they are doing now with burnout) and tightened their relationships with MLBs, they began developing their own assessment and treatment paradigms and selecting 'preferred programs' they wished to work with, some of which their colleagues owned or staffed. Additionally, perhaps due to their reliance on significant funding by the MLB (in one state, the MLB contribution amounts to half of its entire budget), they shifted their primary focus from their earlier emphasis on physician rehabilitation to 'protecting the public', and began aggressively promoting preemptive identification of illness, specialized assessment, lengthy inpatient treatment and extraordinarily extended post-treatment monitoring programs. The scientific validity of the main study supporting the efficacy of this alleged 'gold standard' is debatable.

Once you go to a PHP, whether voluntarily or on order of the MLB or another entity, for what you think is going to be a confidentiality-assured diagnostic intake assessment, you may learn to your dismay and detriment that that assessment was neither truly confidentiality-assured nor even a legitimate psychiatric diagnostic assessment covered by the ethical bounds of such.

Worse, you may discover that you must now go along with everything the PHP says, based on what its 'findings' are, or else you'll be reported to the MLB or your referring institution as non-compliant. And you may discover that that PHP may insist it has the right not to share its diagnostic evaluation findings with you.

You may also learn then that not only might material from your confidential assessment be shared with the MLB or the referring hospital or Accreditation Council for Graduate Medical Education (ACGME) office or even your personal physician, but you could then have your license - whether full or provisional / training - immediately suspended, simply on the basis of the still concealed though incontestable findings of the allegedly immune, exclusively contracted PHP, all conducted behind the valiant banner of needing 'to protect the public'.

The diagnostic evaluations PHPs conduct are inherently of a psychiatric / behavioral health sort, and fall under the general rubric of a Psychological Fitness-For-Duty Evaluation (PFFDE). There is a well-established body of literature defining the clinical and ethical dimensions of such evaluations. It does not appear, as a rule, that PHPs abide by these or perhaps even know they exist. The education and professional licensing requirements of PHP evaluators are quite vague, including whether they are even required to be licensed mental health clinicians or are mandated to undergo annual training in PFFDE guidelines, pertinent healthcare law or ethics. In fact, one may be surprised to learn that the PHP as an organization may not even operate as a recognized medical group or corporation, may carry no medical malpractice insurance, and may operate under the guise of an innocuous educational public charity while conducting questionably legitimate forensic diagnostic psychiatric evaluations as officially designated and effectively employed medical investigators for the MLB.

It is curious that many state PHPs vigorously deny even conducting diagnostic evaluations, masquerading the assessment as a 'peer review' (perhaps doing so as the state legislature may have explicitly limited their scope to such) or as some sort of informal benevolent chat, or a nebulous form of screening that doesn't seem to require a medical license to conduct but nevertheless enjoys the weight of a state sanctioned forensic diagnostic psychiatric evaluation. At best, these would seem to be deceptive practices. Such compulsory mental health evaluations are in reality comparable to an involuntary outpatient civil commitment, albeit conducted under the threat of emergency license suspension, irreparable damage to one's reputation and standing and loss of one's medical career - forever and everywhere. Civilians subjected to involuntary commitment seem to enjoy immensely more robust civil rights protections.

\section{PHP exclusive referral to novel 'preferred programs' with referral propagation}

Alarmingly, while denying physicians access to their evaluation report, PHPs may 'recommend' a referral to a novel out of state 'preferred' four-day diagnostic assessment program, one using non-validated, non-peer reviewed evaluation and consultation methodologies. Nevertheless, that group's diagnostic conclusions are deemed definitive and carry nearly infallible weight with the MLB. Similar to the PHP, they present their purportedly non-diagnostic evaluation as being incontestable.

The nature and protocol of this four-day evaluation remains obscure though some of these innovative centers, for example Acumen Assessments in Lawrence Kansas, feature a polygraph expert on staff. You would be correct in concluding that this is no ordinary mental health program. In fact, to my understanding as a board-certified psychiatrist, no legitimate mental health program in the United States features such. Aside from its 1984ish appearance and mental association with backroom interrogation, the United States Department of Health \& Human Services (USDHHS) and State Departments of Health have wisely recognized that the American Medical Association (AMA) and other bodies long ago dismissed the alleged scientific merits of such examination, placing the practice in much the same category as phrenology. And yet, PHPs and their police-empowered MLBs refuse to confront these wrongful practices and by such refusal essentially endorse their highly questionable methodology and conclusions. Such endorsement further contaminates the already contaminated assessment and adamant refusal to entertain complaint while thwarting access to contested case status in the administrative judicial 
system effectively denies due process to the evaluated physician who contests such.

The contractual and financial connection of these fourday evaluation programs to the referring PHP and its national trade group FSPHP is also obscure but has been called attention to by at least one state auditor who also documented the denial of due process to 1140 physicians just over the ten-year period of review.

Sent out of state for such evaluation, one often has no access to counsel as i) they may not be licensed there; ii) you may have been deprived of external contact as your phone may have been taken from you; and iii) it seems to be implied that because your participation in this ill-defined mental/behavioral assessment program is 'voluntary', there is no need to engage an attorney.

The experience of numerous physicians I and colleagues have spoken with suggests that upon arrival, you are presumed to be an addict 'in denial'. One would have to acknowledge that holding such a diagnostic presumption at admission via an incontestable referral might tend to color the objectivity of the remainder of the $\$ 5000$ consultation.

At the close of one's stay, this program, through some yet to be revealed group consensus process, compiles a report and may 'recommend' that you be referred to a lengthy in-patient program for your newly diagnosed but incontestable condition. Experience suggests that these four day programs too may withhold their records from you for an extended, and critically important, period of time.

\section{The Aggregate PHP Assessment and Recommendation Portfolio}

Upon completion, the referring state PHP receives this preferred program's findings which apparently routinely corroborates the omniscient diagnostic hunch of the purportedly non-diagnosing referring state PHP which then informs the physician client of these definitive findings and recommendations. These recommendations may include extended hospitalization at the same or yet another PHPpreferred center for the newly diagnosed condition. The PHP encourages subject physicians' immediate consent. Absent such, the PHP sends these now purportedly definitive findings and recommendations to the MLB, informing them that the physician is non-compliant with their recommendations. The MLB generally treats the PHP and its preferred partners' diagnostic evaluation findings as unchallengeable and its recommendations as sacrosanct. It may then order complete and prompt compliance under threat of public order for immediate license sanction. And it may additionally issue public charges of unprofessionalism for being non-compliant with the state's sovereignly immune order for definitive treatment of the officially diagnosed mental illness, substance abuse or behavioral health matter in the exact manner prescribed.

Objection to this process is prevented by the Board until it may, at its convenience, schedule a Board hearing on the matter. Unfortunately, the experience of many suggests that these too are inherently biased due process-deprived affairs. Such would seem self-evident if only because of that entity's refusal to disallow the cascade of procedural wrongs which preceded, not the least of which being due process-deprived, methodologically contaminated PFFDEs.

In the interim, the physician is compelled to cooperate with the PHP-defined treatment and monitoring program or have one's license suspended pending hearing.

The financial and psychological burden of just this initial phase of MRTC engagement - PHP assessment; engaging counsel; attending the four-day evaluation; and contesting any aspect of this assessment process - is immense. Alas, it may only be the beginning of an arduous, potentially bankrupting and career-ending ordeal.

\section{No escape - The larger ramifications of these MRTC actions}

If the MLB declares that your license will be restricted if you do not comply, then, should you remain in opposition, your practice (or training) will be abruptly interrupted, patient care may be jeopardized, and you will be deprived of income from your profession. Such loss of income will eventually deprive you of legal representation. Your hospital may suspend your credentials and in doing so may be compelled to report you to the National Practitioner Data Bank (NPDB) for such.

As daunting as things have been thus far, from this point forward, the consequences of challenge to these proceedings only escalate in intensity, career risk and cost.

There appears to be no escape from this Kafkaesque Theater of the Absurd, whether from within the administrative legal system in which the Board operates with nonsupervised police power or within the civil court system. Both judicial systems, the former being termed quasi-judicial, give immense deference to these state entities (i.e. the MLBs and their exclusively contracted PHPs with their entourage of exclusively selected preferred partners). Understandably, these courts presume that they operate in an ethical and law-abiding manner, afford due process, and have both internal and external oversight and legal accountability for wrongdoing. Alas, these appear to be false assumptions but it is not within any one physician complainant's power to establish these deficiencies.

Even without problematic licensing or credentialing questions, if one self-refers (including being 'encouraged' by one's institution or practice), there remain multiple dangers including misdiagnosis, non-maintenance of confidentiality, prevention of self-direction of treatment and funneling into the 'preferred' treatment system and prolonged invasive and costly 'monitoring' accompanied by ongoing fear of the PHP reporting you to the Board for an alleged violation of your 'contract'.

It would appear that nearly any interaction with these non-overseen MRTC entities - MLB, PHP, PR or PA body - poses the immense risk of complicating your profes- 
sional life, tarnishing your reputation, jeopardizing patient care, consuming inordinate financial and psychological resources, and even losing your career forever, everywhere.

\section{Conclusions}

Perhaps one might speculate that this dystopian recounting surely must be the rare exception rather than the rule. One would be forgiven if you found yourself saying No, that can't be! They couldn't (wouldn't) do that!? To me? Just because I have (or had) depression or burnout? Or because I drank too much at a Christmas party and was not on duty? Unfortunately, abundant case interview experience with hundreds of physicians from around the country has revealed such calamitous outcomes from similar unsubstantial or unwarranted causes of engagement.

\section{Implications for physicians seeking mental health or substance abuse care}

Presuming the validity of the foregoing, might these concerns be causing physicians to re-consider whether they want to risk acknowledging a mental health or substance abuse diagnosis on their application or seek assistance from a PHP or even any mental health care professional? Studies strongly suggest so.

On your licensing or credentialing application, you risk the potential consequence of either acknowledging that you are getting - or in the past received - treatment for a condition ... or, answering the intrusive questions negatively so as to not enter into this career-threatening cascade, you risk discovery of your lying about getting treatment. For many, their reasoning is pragmatically expedient. I'm busy; I don't have time to take care of myself. It's already been drilled into me that my needs are secondary to the mission of patient care. I'm seen as weak if I seek help. I ought to be able to overcome this. The risk of this 'either acknowledge ... or lie' option is way too great. So, simplest is - just don't get treatment - that way I don't have to risk exposure and I'll just have to toughen up and find a way to survive this.

Such pragmatism seems entirely reasonable. Unfortunately, as understandable as it is, it can also be disastrous. That one would have to fear getting treatment and therefore suffer the consequences of not getting needed treatment, including deepening depression and suicide, or another worsening mental illness or substance abuse condition, is not just regrettable; it is antithetical to the very principles of the profession of which these physicians are themselves the central healers. To put them in such a bind is unconscionable. To allow such a bind to continue is ethically untenable. That one would avoid seeking critically important - even life-saving - treatment for fear that acknowledging such would then get them sent into the inescapable state-affiliated PHP machinery and provide literally no recourse to object and halt the process and subject it to external review should be of urgent concern to every physician and every leader in healthcare.

A future article will explore potential avenues of recourse. For now, it must suffice to say that if you are a physician, it important that you know that you have a right to be ill, and to get well, and to be protected from this care-seeking jeopardizing your job or your career or your reputation. You must remain vigilant about these potential perils, whether intentional and opportunistic or simply due to the amorality of dangerously defective systems. You have a right to practice according to the dictates of your profession and your patients too have rights to benefit from your continued care. You must take an active and informed role in protecting your and your colleagues' rights - not only to seeking needed care to which you and they are entitled but to a fulfilling medical career free from burdensome, discriminatory and unwarranted punitive or opportunistic intrusion.

\section{References}

1. The Medical Society of New Jersey vs Fred M. Jacobs, MD, JD, and The New Jersey State Board of Medical Examiners. Memorandum of The United States As Amicus Curiae. Civ. A. 93 - 3670 (WGB). Oct. 5, 1993 United States District Court, New Jersey. Available from: https://www.ada.gov/ briefs/mednjbr.pdf

2. Wible P, Palermini A. Physician-friendly states for mental health: a review of medical boards. Pamela Wible MD 2019. Available from: https://www.idealmedicalcare.org/physician-friendly-states-for-mental-health-a-review-of-medicalboards/

3. Goren W. Medical licensing boards, physician health programs, and the lack of ADA compliance: an opportunity for plaintiff lawyers. Understanding the ADA 2019. Available from: https://www.williamgoren.com/blog/2019/07/13/medical-licensing-boards-physician-health-programs-ada-compliance/

4. Reese S. Is it burnout or depression, and does the solution differ? Medscape 2018. Available from: https://www.medscape.com/viewarticle/903025

5. Page L. Burnout might really be depression; how do doctors cope? Medscape 2018. Retrieved from https://www.medscape.com/viewarticle/891005

6. National Academy of Medicine NAM 2018. Establishing clinician well-being as a national priority in Action collaborative on clinician well-being and resilience [Internet] Available from: https://nam.edu/establishing-clinician-wellbeing-as-a-national-priority/

7. Dzau V. Collective action needed to stem burnout and restore clinician well-being and resilience. STAT 2018. Available from: https:/www.statnews.com/2018/02/15/clinicianphysician-burnout-resilience/

8. Federation of State Physician Health Programs 2019. Physician health program guidelines [Internet]. Available from: https://www.fsphp.org/guidelines. 
9. Emmons R, Manion K, Andrew L. Systematic abuse and misuse of psychiatry in the medical regulatory-therapeutic com-plex. J Am Phys Surg. 2018;23:110-4. Available from: http://www.jpands.org/vol23no4/emmons.pdf

10. Skipper G, Specht T. State PHPs protect the public - and save careers. Physician Health News. 2013;18:4. [Newsletter]. Available from: https://www.fsphp.org/assets/docs/ fsphp_newsletter_2013.pdf

11. North Carolina General Assembly. General Statutes. Available from: https://www.ncleg.gov/enactedlegislation/ statutes/pdf/bysection/chapter 90/gs 90-14.pdf

12. Federation of State Medical Boards 2018 Guidelines for the structure and function of a state medical and osteopathic board. Available from: http://www.fsmb.org/siteassets/advocacy/policies/guidelines-for-the-structure-and-functionof-a-state-medical-and-osteopathic-board.pdf

13. Huntoon L. Sham peer review: violations of due process and fundamental fairness. J Am Phys Surg. 2018;23. Available from: https://www.jpands.org/vol23no3/huntoon.pdf
14. Huntoon L. Tactics characteristic of sham peer review. J Am Phys Surg. 2009;14. Available from: https://www.jpands. org/vol14no3/huntoon.pdf

15. DuPont R, Mclellan AT, White WL, et al. Setting the standard for recovery: physicians' health programs. J. Subst. Abuse Treat 2009;36:159-71.

16. American Psychological Association. Professional practice guidelines for occupationally mandated psychological evaluations. Available from: http://www.apa.org/practice/ guidelines/psychological-evaluations.aspx

17. Office of the State Auditor, State of North Carolina. Performance audit - North Carolina physicians health program 2014. Available from: https:/www.auditor.nc.gov/EPSWeb/Reports/Performance/PER-2013-8141.pdf

18. Gold KJ, Andrew LB, Goldman EB, Schwenk TL. "I would never want to have a mental health diagnosis on my record": a survey of female physicians on mental health diagnosis, treatment, and reporting. Gen Hosp Psychiatry 2016;43:51-7. 